\title{
Thermal Effects on the STAR Electromagnetic Calorimeter
}

\author{
T. Fornek,* V. Guarino, H. Spinka, and D. Underwodo \\ High Energy Physics Division \\ Argonne National Laboratory, Argonne, Illinois 60439 271994 \\ OSTI
}

19 July 1994

\section{I) Introduction}

The STAR detector for the RHIC colliding beam accelerator is under construction at Brookhaven National Laboratory. This detector will consist of a number of subsystems as shown in Fig. 1. These include a silicon vertex detector (SVT) for charged particle tracks near the interaction region, a time projection chamber (TPC) for charged particle tracking, an array of plastic scintillation counters (CTB) in a layer around the TPC for triggering on charged particles, a conventional solenoidal magnet, and some additional small triggering detectors along the beamline. An electromagnetic calorimeter (EMC) is an upgrade to the "baseline" detector configuration above. Reference 1 gives a conceptual design for the STAR detector, and Ref. 2 for the EMC.

The conventional magnet and numerous electronic channels for the SVT and TPC subsystems will generate a considerable amount of heat during the operation of STAR. However, it is possible that a chiller for the magnet cooling water will not be available during some of the early STAR runs. As a result, the average magnet temperature may vary considerably between winter and summer. This note sum-

* T. Fornek is on loan from Argonne's Technology Development Division. 
marizes calculations and measurements performed to evaluate the effects of an elevated magnet temperature on the performance of the electromagnetic calorimeter.

The thermal effects include possible deterioration of plastic optical fibers and scintillator tiles (Sec. II), thermal stresses in the EMC support structure (Sec. III), and the EMC barrel modules (Sec. IV), and gain variations in the EMC readout electronics (Sec. VI). Heat flow from the magnet coils to the air in the experimental hall and to the CTB when the EMC is absent, heat transmission through the EMC modules, and the thermal time constant for the calorimeter are also estimated in Sec. V. The expected impact of the elevated magnet temperatures and thermal changes are summarized in Sec. VII.

\section{II) Thermal Effects on EMC Optical Components}

The EMC optical components may experience problems from the high magnet coil temperatures because of close proximity to the coil. For example, the clear plastic optical fibers required to transmit scintillation light from the modules to the photomultipliers will be routed between the magnet coils and may come into contact with them. The EMC module scintillators and the wave-length shifting (WLS) fibers may also be $5-10 \mathrm{~cm}$ from the coils. Thus, it is conceivable that these optical components could be at temperatures approaching the maximum estimated coil temperature of $\sim 125^{\circ} \mathrm{F}=51.7^{\circ} \mathrm{C}$ at the magnet cooling water outlet.

For other calorimeters, scintillator tiles are often annealed after laser cutting to relieve stresses so that microscopic cracks do not propagate and degrade the scintillator light output. For example, the polystyrene scintillator tiles for ZEUS were annealed at $180^{\circ} \mathrm{F}=82.2^{\circ} \mathrm{C}$ (Ref. 3), while the Bicron co-polymer tiles used for SDC tests could not be annealed above $120-125^{\circ} \mathrm{F}$ without mechanical damage. Manufacturing specifications from Bicron (Ref. 4) indicate acceptable operating temperatures for light output up to $\geq 120^{\circ} \mathrm{F}=48.9^{\circ} \mathrm{C}$ for various types of scintillator, 


\section{DISCLAIMER}

This report was prepared as an account of work sponsored by an agency of the United States Government. Neither the United States Government nor any agency thereof, nor any of their employees, makes any warranty, express or implied, or assumes any legal liability or responsibility for the accuracy, completeness, or usefulness of any information, apparatus, product, or process disclosed, or represents that its use would not infringe privately owned rights. Reference herein to any specific commercial product, process, or service by trade aame, trademark, manufacturer, or otherwise does not necessarily constitute or imply its endorsement, recommendation, or favoring by the United States Government or any agency thereof. The views and opinions of authors expressed herein do not necessarily state or reflect those of the United States Government or any agency thereof. 


\section{DISCLAIMER}

Portions of this document may be illegible in electronic image products. Images are produced from the best available original document. 
especially if the scintillator is in an oxygen-deficient atmosphere. Finally, distortion of the plastic scintillator tiles may occur at elevated temperatures if there are nonuniform loads on the tiles, which could indirectly affect the light transmitted to the WLS fibers. In summary, temperature effects are sensitive to both the type of plastic scintillator and to the loads on the tiles.

A simple test of a $3 \mathrm{~mm}$ thick, $10.5 \mathrm{~cm} \times 11 \mathrm{~cm}$ copolymer scintillator plate or tile from Bicron was performed. The scintillator was supported on opposite edges in an oven at $158^{\circ} \mathrm{F}=70^{\circ} \mathrm{C}$ for 13 weeks. A warpage of the tile became apparent as shown in Fig. 2 due to gravitational loading. This test illustrates possible mechanical problems of elevated temperatures.

The WLS fibers will be in contact with the plastic scintillator tiles and may extend $\approx 50 \mathrm{~cm}$ before being bonded to clear plastic fibers, which have much longer attenuation lengths. For the scintillators near the outer radius of the EMC, these WLS fibers may be located within a few $\mathrm{cm}$ of the magnet coils. It has also been suggested to use WLS fibers all the way to the photomultipliers under some circumstances. Information on thermal effects to these fibers from Bicron (Ref. 4) indicate there should be no significant change in optical properties for temperatures up to at least $120^{\circ} \mathrm{F}$.

Tests of light output from three WLS fibers have been performed at $120^{\circ} \mathrm{F}=$ $48.9^{\circ} \mathrm{C}$. A BCF-91 fiber was heated for 15 weeks, but failed within six days. Two BCF-91-a fibers were heated, one for 15 and the other for 21 weeks. Both exhibited the same light output over the time of the test within measurement uncertainties. An unheated BCF-91 fiber also failed within a week. The uncorrected and corrected light outputs are shown in Fig. 3 from these measurements. It is concluded that the differences in chemical compositions, such as between BCF-91 and BCF-91a, can seriously affect light output from WLS fibers. 
A clear plastic optical fiber was also tested at $120^{\circ} \mathrm{F}$ for 21 weeks. Tests of light transmission indicated negligible change. This test was conducted with the fiber circled into a radius of $\sim 3 \mathrm{~cm}$ to enhance possible degradation effects when the fibers are stressed. Information from Bicron (Ref. 4) suggests safe operating temperatures up to $120^{\circ} \mathrm{F}=48.9^{\circ} \mathrm{C}$.

If the calorimeter temperature will change significantly from summer to winter, the calibration of the EMC will become more difficult. For example, the scintillator light output may change, or the optical fiber transmission may be temperature dependent. These thermal effects are likely to be dependent on the type of fiber and scintillator, as well. Finally, variations in temperature may lead to movement of optical components due to thermal expansion effects, and this movement may affect the light transmission to the photomultipliers.

In conclusion, the most serious problems for optical components appear to be degradation of WLS fiber performance at elevated temperatures, deformation of plastic scintillator tiles if not uniformly loaded, and changes to EMC calibrations. So far, measurements have been performed with very few samples and for relatively short times compared to the estimated lifetime of STAR $(\approx 20$ years $)$. Thus, the full range and magnitude of the problems may not have been uncovered.

\section{III) Thermal Effects in the EMC Support Structure}

The barrel electromagnetic calorimeter will be supported from the magnet flux return bars or backleg steel bars using aluminum rings as shown in Fig. 4. These rings will be located between the magnet coils. Their design is further described in Refs. 2,5,6. Rails attached to the rings as shown in Fig. 5 will allow the EMC modules to be installed with relatively little disturbance to the SVT, TPC, or CTB subsystems. The QUICKSLIDE 2DA-16 system manufactured by Thomson Industries, Inc. is being considered for the rails. Each rail would consist of a pair of 
parallel $25.4 \mathrm{~mm}=1.00 "$ diameter "nonmagnetic" stainless steel rods mounted to an extruded aluminum support. Several matching carriages with rulon plastic bushings would be attached to each EMC module.

A number of finite element calculations were performed for thermal effects on the rings and rails. These used the commercial computer program COSMOS, version 1.65A, on an ALR 486 personal computer or workstation with a $310 \mathrm{Mb}$ hard disk drive.

The present conceptual design for the EMC support rings (Ref. 6) has separate designs for the center ring and for the other eight rings. They are to have a "C"-shaped cross section of thickness $70 \mathrm{~mm}=2.75$ " for each of the eight rings, and two C-shaped sections of $44 \mathrm{~mm}=1.75^{\prime \prime}$ each for the center ring; see Fig. 6 . They will be supported in 16 locations on their outer radius from the magnet flux return bars, and the rings are to be uniformly spaced as shown in Fig. 4.

The finite element models for these rings were constructed of brick or volume elements in a $3 \times 12$ pattern for both the 1.75" and 2.75" rings as shown in Fig. 7 . The 16 support points were taken to be FIXED in the models, by requiring four nodes to be fixed. Only half of the ring was modeled because of symmetry. Loads to the rings were transferred from the EMC module center of gravity with rigid, massless beam elements connected to the rings at one node per module. These calculations used "worst case" EMC gravitational loads of 600 and $825 \mathrm{lb}$. at the center and end rings, respectively.

Various loading and thermal cases were considered as shown in Table 1. Stresses in the rings due to gravitational loads alone were quite small, with maxima of $\sim 2300$ psi for both ring thicknesses; see Fig. 8. The average ring stress was considerably less, and maximum deflections were also small $(\leq 0.23 \mathrm{~mm}=0.009 ")$. The highest stresses occurred close to the ring support and rail support nodes. 
In order to consider worst case situations, it was assumed that the EMC support structure would be assembled at a room temperature of $\sim 65^{\circ} \mathrm{F}=18.3^{\circ} \mathrm{C}$ during the winter. Then the normal magnet operating temperature of $\sim 85^{\circ} \mathrm{F}=29.4^{\circ} \mathrm{C}$ would correspond to a rise of $20^{\circ} \mathrm{F}$. With this temperature rise, the maximum calculated stresses were 13,600 psi (Fig. 9) and 12,200 psi for the 1.75" and 2.75" thick rings, respectively. The maximum deflections were along the beam direction or detector axis, and were $0.30 \mathrm{~mm}=0.012 "$ and $0.58 \mathrm{~mm}=0.023^{\prime \prime}$. The highest stresses occurred at the fixed ring support nodes.

An alternate ring design with a rectangular cross section was also considered. The finite element models were similar to those above, except there were $2 \times 8$ volume elements used for the cross section of either the thin or thick rings. Deflections were small in all cases $(\leqslant 0.20 \mathrm{~mm}=0.008 ")$. Maximum stresses were $\sim 13,400$ and 12,600 psi for a $20^{\circ} \mathrm{F}$ temperature rise, and $\sim 30,200$ (Fig. 10) and 29,100 psi for a $50^{\circ} \mathrm{F}$ rise. The previous stresses correspond to the thin and thick rings, respectively, and the highest values are concentrated at the nodes where the fixed supports to the magnet flux return bars or backleg steel bars occur; see Figs. 7 and 8 . Stresses away from these nodes are considerably smaller.

The $50^{\circ} \mathrm{F}=27.8^{\circ} \mathrm{C}$ temperature rise would correspond to an average magnet temperature of $115^{\circ} \mathrm{F}=46.1^{\circ} \mathrm{C}$ during summer with no chiller for the magnet cooling water (Ref. 7). The stresses calculated for a $50^{\circ} \mathrm{F}$ temperature rise are above acceptable limits for aluminum. These limits are $2 / 3$ of the yield strength for the case of combined thermal and gravitational loads, and $1 / 3$ of the yield strength for gravitational loads alone (Ref. 8). In the case of combined thermal and gravitational loads, the limits are $\sim 18,000$ psi for wrought and $\sim 14,000$ psi for cast aluminum. The present conceptual design for the rings given in Ref. 6 assumes they are assembled from cast $60^{\circ}$ sections, so they would work acceptably for a $20^{\circ} \mathrm{F}=11.1^{\circ} \mathrm{C}$ temperature rise. 
A comparison of the C-shaped and rectangular cross section rings shows similar maximum stresses, lower maximum deflections, and somewhat higher average stresses for the latter. In both cases, the assumption that the supports to the magnet flux return bars are fixed leads to quite small deflections. However, modeling these supports as fixed points may give unrealistically high ring stresses, since the bars will also experience some thermal effects. In any case, several schemes are being studied to reduce these stresses by designing ring support systems which allow the rings to expand at higher temperatures. For example, spring-loaded bolts or "Belleville washers" may be used in the supports. It is also possible to make the rings segmented instead of continuous, or to assemble the EMC support structure at an elevated room temperature.

\section{IV) Thermal Effects in the EMC Modules}

The barrel EMC modules will consist of 21 layers of $4 \mathrm{~mm}$ thick plastic scintillator alternating with 20 lead sheets of thickness $5 \mathrm{~mm}$; see Ref. 2. These materials will be supported by the module structural members which include a $20 \mathrm{~mm}$ thick front plate at the EMC inner radius, a $30 \mathrm{~mm}$ back plate, two $3.18 \mathrm{~mm}=$ 0.125 " end plates, a $6.35 \mathrm{~mm}=0.25^{\prime \prime}$ center bulkhead, and two $0.5 \mathrm{~mm}=0.020^{\prime \prime}$ side sheets. All structural members will be "nonmagnetic" stainless steel, except the front plate which will be aluminum. Previous finite element calculations of the EMC modules under gravitational and seismic loads have indicated acceptable stresses in all structural members. The seismic loads are taken to be 0.15 times the weight, and these are applied only in the horizontal directions.

The ALGOR finite element analysis computer code (version SSAPOH dated $12 / 30 / 92$ ) was used to perform the calculations with a $486 / 33$ personal computer and $80 \mathrm{Mb}$ of available hard disk space. Plate elements were used for all structural members, as shown in Fig. 11. The weight of the lead and scintillator (1,700 lb. per 
module) was incorporated by increasing the densities of the module ends and center bulkhead to correspond to the fraction of the load expected at these three structural members. The model was fixed at the nodes corresponding to the center rail support. At the four other rail supports, the nodes were allowed to move along the rails or the beam direction, but were constrained in the other two directions. Note that the present design does not include a rail support at the end of the module farthest from the center of the STAR detector.

Two thermal cases were considered; see Table 2. Both had a uniform temperature for the front and for the back plate. One case had the back plate $20^{\circ} \mathrm{F}$ $=11.1^{\circ} \mathrm{C}$ hotter, and the other had it $20^{\circ} \mathrm{F}$ colder than the front plate. The magnitudes of the thermal stresses in the two cases were essentially equal. The computed stresses are shown in Fig. 12 for the case of seismic and gravitational loads only, Fig. 13 for thermal loads only, and Fig. 14 for combined loads. Of all the cases studied, the highest stresses were observed for the module at the 10:30 o'clock location and their combined gravitational, seismic, and thermal loads as in Fig. 14. The thermal stresses are always much larger than gravitational stresses, with the maximum values occurring in the side sheets; see Figs. 13 and 14.

The maximum stresses are also closer to the allowable limits for combined thermal, seismic, and gravitational loads; these limits are $2 / 3$ of the yield strength (Ref. 8). Therefore, the present EMC module design will allow temperature differences of up to $20^{\circ} \mathrm{F}=11.1^{\circ} \mathrm{C}$ from the front to the back plate; higher temperature differences might lead to module deformation.

\section{V) Analvtical Estimates of Thermal Effects}

Analytical calculations were performed for a variety of thermal effects. In one case, the heat transmitted from the magnet to the air in the experimental hall was estimated. The room temperature was taken to be $70^{\circ} \mathrm{F}=11.1^{\circ} \mathrm{C}$. The magnet 
flux return bars were assumed to be at the maximum value of the average magnet temperature, or $115^{\circ} \mathrm{F}=46.1^{\circ} \mathrm{C}$. The convection coefficient for the air was 2 $\mathrm{Btu} /{ }^{\circ} \mathrm{F} / \mathrm{ft}^{2}$, and this gave a convection heat transmission of $1.607 \times 10^{5} \mathrm{Btu}$. This additional heat would require an increased air conditioning capacity of 13.4 tons.

A second calculation was the steady state heat transmitted from the magnet coils to the CTB without the EMC modules in place. The CTB scintillators and associated electronics will be located in water cooled boxes, assumed to be aluminum, to maintain constant temperatures and to minimize photomultiplier gain changes. The coil temperature was assumed to be $115^{\circ} \mathrm{F}=46.1^{\circ} \mathrm{C}$ and the $\mathrm{CTB}$ to be $75^{\circ} \mathrm{F}=23.4^{\circ} \mathrm{C}$. Both radiation and convection through the air gap between them were considered. The total heat transfer was $4.05 \mathrm{Btu} / \mathrm{sec}=4.3 \mathrm{~kW}$, with 0.45 $\mathrm{Btu} / \mathrm{sec}$ from radiation and $3.6 \mathrm{Btu} / \mathrm{sec}$ from convection. This heat load, as well as the heat from the CTB electronics, would need to be removed from the CTB boxes by the cooling water if no EMC modules were in place.

This same type of calculation was repeated with the EMC modules between the magnet coils and the CTB. Heat transfer from the magnet coils to the outer radius of the EMD modules was taken to occur by conduction and convection through the air, radiation, and conduction through the EMC support rings, rails, and carriages; see Fig. 15. Conduction through the EMC support is difficult to model accurately, and the estimated heat transfer may change significantly with modifications to the support configuration. Conduction is the only heat transmission mechanism assumed through the EMC modules; air gaps between layers of scintillator and lead are ignored. Such air gaps are likely to reduce the heat transfer significantly. Finally, conduction and convection through the air and radiant heat transfers were estimated for the space between the inner radius of the EMC and the outer radius of the CTB boxes. 
The overall heat transfer from the magnet coils to the CTB was obtained by iteration with a computer program. The total heat transmission was computed to be $2.5,1.8$, and $1.2 \mathrm{~kW}$ for an average magnet coil temperature of $115^{\circ} \mathrm{F}=46.1^{\circ} \mathrm{C}$, $105^{\circ} \mathrm{F}=40.6^{\circ} \mathrm{C}$ and $95^{\circ} \mathrm{F}=35^{\circ} \mathrm{C}$, respectively. Table 3 gives the computed temperatures and heat transfers at various locations as shown in Fig. 15. At a magnet temperature of $115^{\circ} \mathrm{F}$, the EMC modules are expected to reduce the heat flow by approximately $4.3-2.5=1.8 \mathrm{~kW}$, or $40 \%$. In all cases, the conduction through the EMC support is the main contribution $(\sim 70-75 \%)$ to the heat transmission, while conduction in the air between the coil and the EMC is negligible.

An estimate of the thermal time constant for the EMC modules can be made from the data in Table 3, and the specific heats and masses of the materials in the modules. When the magnet and electronics are turned off, the temperature on both sides of the gap between the magnet coil inner radius and EMC outer radius will be $\mathrm{T}_{0}$. When the magnet is powered, it is assumed to quickly reach the operating temperature $\mathrm{T}_{1}$, and to act as a heat source. The temperature of the outer radius of the EMC (see Fig. 15) will be approximately

$$
\mathrm{T}_{2} \cong \mathrm{T}_{\mathrm{f}}+\left(\mathrm{T}_{\mathrm{o}}-\mathrm{T}_{\mathrm{f}}\right) \mathrm{e}^{-t / \tau}
$$

where $T_{\mathrm{f}}$ is the final steady state temperature from Table 3 and $\tau$ is the thermal time constant. Both the steady state temperature difference $\Delta \mathrm{T}_{\mathrm{ss}}=\mathrm{T}_{1}-\mathrm{T}_{\mathrm{f}}$ and the steady state heat flow $\dot{Q}_{s s}$ are given for three values of $T_{1}$ in Table 3. Since conduction dominates the heat flow in the gap, the heat flow is assumed proportional to the temperature difference,

$$
\dot{\mathrm{Q}}_{12}=\left(\mathrm{T}_{1}-\mathrm{T}_{2}\right) \cdot \frac{\dot{\mathrm{Q}}_{\mathrm{ss}}}{\Delta \mathrm{T}_{\mathrm{ss}}}
$$

\section{DISCLAIMER}

This report was prepared as an account of work sponsored by an agency of the United States Government. Neither the United States Government nor any agency thereof, nor any of their employees, makes any warranty, express or implied, or assumes any legal liability or responsibility for the accuracy, completeness, or usefulness of any information, apparatus, product, or process disclosed, or represents that its use would not infringe privately owned rights. Reference herein to any specific commercial product, process, or service by trade name, trademark, manufacturer, or otherwise does not necessarily constitute or imply its endorsement, recommendation, or favoring by the United States Government or any agency thereof. The views and opinions of authors expressed herein do not necessarily state or reflect those of the United States Government or any agency thereof 
The maximum heat flow across the gap, $\dot{\mathrm{Q}}_{\max }$, occurs when $\mathrm{T}_{2}=\mathrm{T}_{0}$. The "average" heat flow during the transition to steady state conditions is roughly $\dot{\mathrm{Q}}_{\mathrm{AV}}=\left(\dot{\mathrm{Q}}_{\max }+\right.$ $\dot{\mathrm{Q}}_{\mathrm{ss}} / 2$, and the approximate heat available to warm the module is $\dot{\mathrm{Q}}_{\mathrm{H}}=\dot{\mathrm{Q}}_{\mathrm{AV}}-\dot{\mathrm{Q}}_{\mathrm{ss}}$. Then an estimate for the thermal time constant $\tau$ is

$$
\tau \approx\left(\sum_{j} \mathrm{~m}_{j} \mathrm{c}_{\mathrm{j}} \Delta \mathrm{T}_{\mathrm{j}}\right) / \dot{\mathrm{Q}}_{\mathrm{H}}
$$

where the sum is over the masses, specific heats, and temperature rises of all materials in the EMC modules. When this calculation is performed using the three cases in Table 3 , it is found that

$$
\tau \approx 22-24 \text { hours } \approx 1 \text { day. }
$$

\section{VI) Thermal Effects in EMC Readout Electronics}

It is well known that the gains of photomultipliers changes with temperature. There can also be variations in properties of electronic components with temperature. As a result, it is planned to mount the photomultipliers and electronics inside temperature-regulated boxes mounted to the outside of the magnet flux return bars. Water cooling lines are planned to be mounted to the sides of each box to provide the temperature regulation. These boxes may be constructed of iron for additional magnetic shielding of the photomultipliers. No significant problems are anticipated from short or long term changes in magnet temperature due to thermal effects in EMC readout electronics.

\section{VII) Summary}

A number of thermal effects have been considered for the STAR electromagnetic calorimeter. Temperature differences of up to about $20^{\circ} \mathrm{F}=11.1^{\circ} \mathrm{C}$ above room 
temperatures are generally expected to cause only gain changes for the scintillator light yield. It is planned to install the EMC readout photomultipliers and electronics in temperature controlled boxes to minimize gain changes from thermal variations in these components. Larger temperature differences will lead to excessive stresses in the EMC support rings; these stresses may perhaps be reduced by modifications to the present design for the rings. Temperature differences above $20^{\circ} \mathrm{F}$ across the EMC modules will also produce excessive stresses, but these will correspond to $\approx 50^{\circ} \mathrm{F}$ temperature differences between the magnet coils and the CTB.

Elevated temperatures will also lead to problems with optical components, such as wave-length shifting plastic optical fibers and plastic scintillator tiles. Some tests indicate that serious problems begin at temperatures as low as $120^{\circ} \mathrm{F}=$ $48.9^{\circ} \mathrm{C}$ for short-term effects; presumably even lower temperatures will cause changes over the estimated 20 year lifetime of STAR unless other materials can be shown to withstand higher temperatures.

\section{ACKNOWLEDGEMENTS}

We wish to thank Bill Edwards, Norm Hill, Don Jankowski, Joseph Rasson, other members of the Argonne TD and HEP Divisions and of the STAR magnet, integration, and calorimeter subgroups, and especially E. Bielick for many useful discussions concerning thermal effects on the EMC components. The work of Don Jankowski on a pair of the figures is gratefully acknowledged. This work was supported by the U.S. Department of Energy, Division of High Energy Physics, Contract W-31-109-ENG-38 and by R\&D funding for the RHIC project 


\section{REFERENCES}

1. "STAR Conceptual Design Report," Lawrence Berkeley Laboratory report PUB-5347, (1992).

2. "The Electromagnetic Calorimeter for the Solenoidal Tracker at RHIC A Conceptual Design Report," Lawrence Berkeley Laboratory report PUB-5380, (1993).

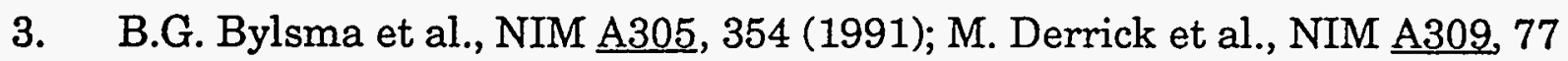
(1991).

4. Private communication with W. Moser, Bicron.

5. "Calculations on the STAR Conventional Magnet Design," T. Formek, H. Spinka, and D. Underwood, Argonne National Laboratory report ANL-HEP-TR-93-45 and STAR Note \# 115, (1993).

6. "Conceptual Design for the STAR Barrel Electromagnetic Calorimeter Support Rings," E. Bielick, T. Fornek, H. Spinka, and D. Underwood, Argonne National Laboratory report ANL-HEP-TR-94-13 and STAR Note \# 154, (1994).

7. $\quad$ "STAR Magnet Maximum Operating Temperature," J. Rasson, STAR Note \# 147, (1994).

8. Private communication with W. R. Edwards. 


\section{Table 1}

\section{Summary of Finite Element Calculations of the STAR Support Rings}

\begin{tabular}{|c|c|c|c|c|c|}
\hline \multirow[b]{2}{*}{$\Delta T$} & \multirow[b]{2}{*}{ Ring Type } & \multirow[b]{2}{*}{ Thickness } & \multicolumn{2}{|c|}{$\begin{array}{l}\text { Maximum } \\
\text { Deflections } \\
\end{array}$} & \multirow[b]{2}{*}{ Maximum Stress } \\
\hline & & & $Z$ & Vertical & \\
\hline \multirow[t]{5}{*}{0} & C - supported at 16 points & $1.75^{\prime \prime}$ & $0.009^{\prime \prime}$ & $0.001^{\prime \prime}$ & \begin{tabular}{|c|}
2300 psi \\
At the bottom support point
\end{tabular} \\
\hline & $\mathrm{C}$ - supported at 16 points & $2.75^{\prime \prime}$ & $0.007^{\prime \prime}$ & $0.001^{\prime \prime}$ & $\begin{array}{c}2300 \text { psi } \\
\text { At the bottom support point }\end{array}$ \\
\hline & $\begin{array}{c}\text { C - supported at top and } \\
\text { bottom only }\end{array}$ & $2.75^{\prime \prime}$ & $0.035^{\prime \prime}$ & $0.056^{\prime \prime}$ & $\begin{array}{c}9900 \text { psi at the } \\
\text { top and bottom support } \\
\text { point }\end{array}$ \\
\hline & $\begin{array}{c}\text { Rectancular - } \\
\text { Supported at } 16 \text { points } \\
\end{array}$ & $2.75^{\prime \prime}$ & $0.002^{\prime \prime}$ & $0.001^{\prime \prime}$ & 1600 psi at the supports \\
\hline & $\begin{array}{c}\text { Rectangular - } \\
\text { Supported at top and } \\
\text { bottom only }\end{array}$ & $2.75^{\prime \prime}$ & $0.009^{\prime \prime}$ & $0.029^{\prime \prime}$ & $\begin{array}{l}4700 \text { psi at the top and } \\
\text { bottom support points }\end{array}$ \\
\hline \multirow[t]{5}{*}{$20^{\circ} \mathrm{F}$} & $\mathrm{C}$ - supported at 16 points & $1.75^{\prime \prime}$ & $0.012^{\prime \prime}$ & $0.003^{\prime \prime}$ & $\begin{array}{c}13600 \text { psi } \\
\text { At the supports }\end{array}$ \\
\hline & $\mathrm{C}$ - supported at 16 points & $2.75^{\prime \prime}$ & $0.023^{\prime \prime}$ & $0.004^{\prime \prime}$ & $\begin{array}{l}12200 \text { psi } \\
\text { At the bottom support point }\end{array}$ \\
\hline & $\begin{array}{c}\text { Rectangular - } \\
\text { Supported at } 16 \text { points }\end{array}$ & $1.75^{\prime \prime}$ & $0.006^{\prime \prime}$ & $0.003^{\prime \prime}$ & $\begin{array}{l}13400 \text { psi } \\
\text { At the bottom support point }\end{array}$ \\
\hline & $\begin{array}{c}\text { Rectangular - } \\
\text { Supported at } 16 \text { points }\end{array}$ & $2.75^{\prime \prime}$ & $0.003^{\prime \prime}$ & $0.004^{\prime \prime}$ & $\begin{array}{l}12600 \text { psi } \\
\text { At the bottom support point }\end{array}$ \\
\hline & $\begin{array}{l}\text { Rectangular - Supported } \\
\text { at } 16 \text { points - finer mesh }\end{array}$ & $2.75^{\prime \prime}$ & $0.003^{\prime \prime}$ & $0.004^{\prime \prime}$ & $\begin{array}{l}15000 \text { psi } \\
\text { At the bottom support point }\end{array}$ \\
\hline $50^{\circ} \mathrm{F}$ & $\begin{array}{c}\text { Rectangular - } \\
\text { Supported at } 16 \text { points }\end{array}$ & $1.75^{\prime \prime}$ & $0.006^{\prime \prime}$ & $0.008^{\prime \prime}$ & $\begin{array}{l}30200 \text { psi } \\
\text { At the bottom support point }\end{array}$ \\
\hline & $\begin{array}{c}\text { Rectangular - } \\
\text { Supported at } 16 \text { points }\end{array}$ & $2.75^{\prime \prime}$ & $0.004^{\prime \prime}$ & $0.008^{\prime \prime}$ & $\begin{array}{l}29100 \mathrm{psi} \\
\text { At the bottom support point }\end{array}$ \\
\hline
\end{tabular}




\section{Table 2}

Summary of Thermal Calculations for EMC Modules

The gravitational and seismic loads are applied parallel to the solenoid axis (z), from the back to the front plate (y), and to the side parallel to the lead plates (x). Seismic loads of $0.15 \mathrm{~g}$ are applied in the horizontal plane. Thermal differences of $+20^{\circ} \mathrm{F}$ and $-20^{\circ} \mathrm{F}$ refer to the front or back plate being hotter, respectively.

\begin{tabular}{|c|c|c|c|c|c|c|}
\hline \multirow[b]{2}{*}{ Case } & \multirow[b]{2}{*}{$\Delta T$} & \multicolumn{2}{|c|}{ Loads } & \multirow[b]{2}{*}{$\mathbf{z}$} & \multirow[b]{2}{*}{ Max Stress } & \multirow[b]{2}{*}{ Approx. Position } \\
\hline & & $\mathbf{x}$ & $\mathbf{y}$ & & & \\
\hline 1 & 0 & 0 & $1.0 \mathrm{~g}$ & 0 & $5400 \mathrm{psi}$ & 12 o'clock \\
\hline 2 & 0 & $1.15 \mathrm{~g}$ & 0 & 0 & 3900 psi & 3 o'clock \\
\hline 3 & 0 & 0 & $1.0 \mathrm{~g}$ & $0.15 \mathrm{~g}$ & $4700 \mathrm{psi}$ & $\begin{array}{c}12 o^{\prime} \text { clock - includes } \\
\text { seismic }\end{array}$ \\
\hline 4 & 0 & $1.15 \mathrm{~g}$ & 0 & $0.15 \mathrm{~g}$ & $3800 \mathrm{psi}$ & $\begin{array}{c}3 \text { o'clock - includes } \\
\text { seismic }\end{array}$ \\
\hline 5 & 0 & 0 & 0 & $0.15 \mathrm{~g}$ & $1100 \mathrm{psi}$ & Only seismic \\
\hline 6 & $+20^{\circ} \mathrm{F}$ & 0 & 0 & 0 & $15500 \mathrm{psi}$ & Thermal only \\
\hline 7 & $-20^{\circ} \mathrm{F}$ & 0 & 0 & 0 & $15500 \mathrm{psi}$ & Thermal only \\
\hline 8 & $-20^{\circ} \mathrm{F}$ & 0 & $1.0 \mathrm{~g}$ & $0.15 \mathrm{~g}$ & $15900 \mathrm{psi}$ & $\begin{array}{c}12 \text { o'clock - includes } \\
\text { seismic }\end{array}$ \\
\hline 9 & $-20^{\circ} \mathrm{F}$ & $1.10 \mathrm{~g}$ & 0 & $0.15 \mathrm{~g}$ & $16100 \mathrm{psi}$ & $\begin{array}{c}3 \text { o'clock - includes } \\
\text { seismic }\end{array}$ \\
\hline 10 & $+20^{\circ} \mathrm{F}$ & $0.81 \mathrm{~g}$ & $0.71 \mathrm{~g}$ & $0.15 \mathrm{~g}$ & $16600 \mathrm{psi}$ & 1:30 o'clock + seismic \\
\hline 11 & $+20^{\circ} \mathrm{F}$ & $0.81 \mathrm{~g}$ & $0.71 \mathrm{~g}$ & $-0.15 \mathrm{~g}$ & 16400 psi & 1:30 o'clock + seismic \\
\hline 12 & $+20^{\circ} \mathrm{F}$ & $-0.81 \mathrm{~g}$ & $0.71 \mathrm{~g}$ & $0.15 \mathrm{~g}$ & $16800 \mathrm{psi}$ & 10:30 o'clock + seismic \\
\hline 13 & $+20^{\circ} \mathrm{F}$ & $-0.81 \mathrm{~g}$ & $0.71 \mathrm{~g}$ & $-0.15 \mathrm{~g}$ & $16600 \mathrm{psi}$ & 10:30 o'clock + seismic \\
\hline 14 & $-20^{\circ} \mathrm{F}$ & $-0.81 \mathrm{~g}$ & $0.71 \mathrm{~g}$ & $0.15 \mathrm{~g}$ & $15900 \mathrm{psi}$ & 10:30 o'clock + seismic \\
\hline
\end{tabular}

A number of other cases were also studied, but they gave lower stresses than some of the cases above. 


\section{Table 3}

\section{Steady State Heat Flow Through an EMC Module}

The model used and the location of the temperatures $\mathrm{T}_{1}-\mathrm{T}_{6}$ are shown in Fig. 15 The convection assumes that the EMC module is located at the bottom of the STAR barrel. A 24" long segment of the EMC is assumed. Additional details are given in the text.

$\begin{array}{cccc}\mathrm{T}_{1}= & \mathbf{9 5}^{\circ} \mathrm{F} & \mathbf{1 0 5}{ }^{\circ} \mathrm{F} & \mathbf{1 1 5} \mathrm{F} \\ \mathrm{T}_{2} & 90.8^{\circ} \mathrm{F} & 98.6^{\circ} \mathrm{F} & 106.3^{\circ} \mathrm{F} \\ \mathrm{T}_{3} & 90.8^{\circ} \mathrm{F} & 98.5^{\circ} \mathrm{F} & 106.2^{\circ} \mathrm{F} \\ \mathrm{T}_{4} & 85.5^{\circ} \mathrm{F} & 90.3^{\circ} \mathrm{F} & 95.0^{\circ} \mathrm{F} \\ \mathrm{T}_{5} & 85.5^{\circ} \mathrm{F} & 90.3^{\circ} \mathrm{F} & 95.0^{\circ} \mathrm{F} \\ \mathrm{T}_{6} & 75.0^{\circ} \mathrm{F} & 75.0^{\circ} \mathrm{F} & 75.0^{\circ} \mathrm{F}\end{array}$

$\dot{\mathrm{Q}}_{12}$

$\begin{array}{cccc}\text { Conduction } & 5.03 \mathrm{Btu} / \mathrm{hr} & 7.74 \mathrm{Btu} / \mathrm{hr} & 10.50 \mathrm{Btu} / \mathrm{hr} \\ \text { Radiation } & 0.60 & 0.97 & 1.38 \\ \text { Convection } & 1.03 & 1.63 & 2.24\end{array}$




\section{Figure Captions}

Figure 1 Quarter sectional drawing of the STAR detector showing the location of some of the STAR subsystems. These include the solenoidal magnet, time projection chamber (TPC), silicon vertex tracker (SVT), charged trigger barrel (CTB), and related electronics, as well as the electromagnetic calorimeter (EMC).

Figure 2

Photograph of a copolymer scintillator tile after heating. Note the warpage.

Figure 3

Measurements of relative light transmission through various plastic optical fibers as a function of time. The data are shown (a) uncorrected, and (b) corrected for variations in the output of the light source. Some of the fibers were heated to $120^{\circ} \mathrm{F}$ for these tests, while others remained at room temperature to serve as controls.

Figure 4

Drawing showing planned locations for the EMC support rings, barrel EMC modules and related electronics, and endcap EMC sections.

Figure 5 Conceptual design of one rail and ring system for the EMC support, showing the relative locations of the rails in the STAR detector.

Figure 6

Cross sections for the EMC support rings assumed for some of the thermal calculations presented in this report. Both the center ring (lower) and the remaining ring (upper) cross sections are shown.

Figure 7

Finite element grid used to model the EMC support rings. The same grid was used with different dimensions of the elements for the center and the other ring calculations. 
Figure 8

Figure 9

Figure 10

Figure 11

Figure 12

Figure 13

Figure 14

Figure 15
Stresses in the thin, center ring estimated from gravitational loading by the EMC modules by the finite element calculation.

Stresses in the thin, center ring estimated from combined thermal and gravitational leads due to the EMC modules. A temperature difference $\Delta \mathrm{T}=20^{\circ} \mathrm{F}$ was assumed for this finite element calculation.

Stresses in the thin, center ring using combined thermal and gravitational loads from a finite element model. The ring cross section was taken to be rectangular and the temperature difference $\Delta \mathrm{T}=50^{\circ} \mathrm{F}$.

Finite element grid used to model the EMC barrel modules. All elements are assumed to be plate elements.

Stresses in the EMC barrel module structural elements due to gravitational and seismic (15\% of gravitational) loads only. The stresses were estimated using a finite element calculation using the model in Fig. 11. The module is assumed at the 10:30 o'clock location.

Stresses in the EMC barrel module due to thermal loads only from a finite element calculation. A temperature difference $\Delta \mathrm{T}=$ $20^{\circ} \mathrm{F}$ was assumed.

Stresses in the EMC barrel module due to combined thermal, gravitational, and seismic loads. A $20^{\circ} \mathrm{F}$ temperature difference was assumed in the finite element calculation. The module is assumed at the 10:30 o'clock location.

Sketch showing the various heat transfer mechanisms assumed for the calculation of heat flow through the EMC modules, support rings, and air. The temperatures at various locations, designated $\mathrm{T}_{1}-\mathrm{T}_{6}$, are presented in Table 3 for several initial conditions. 







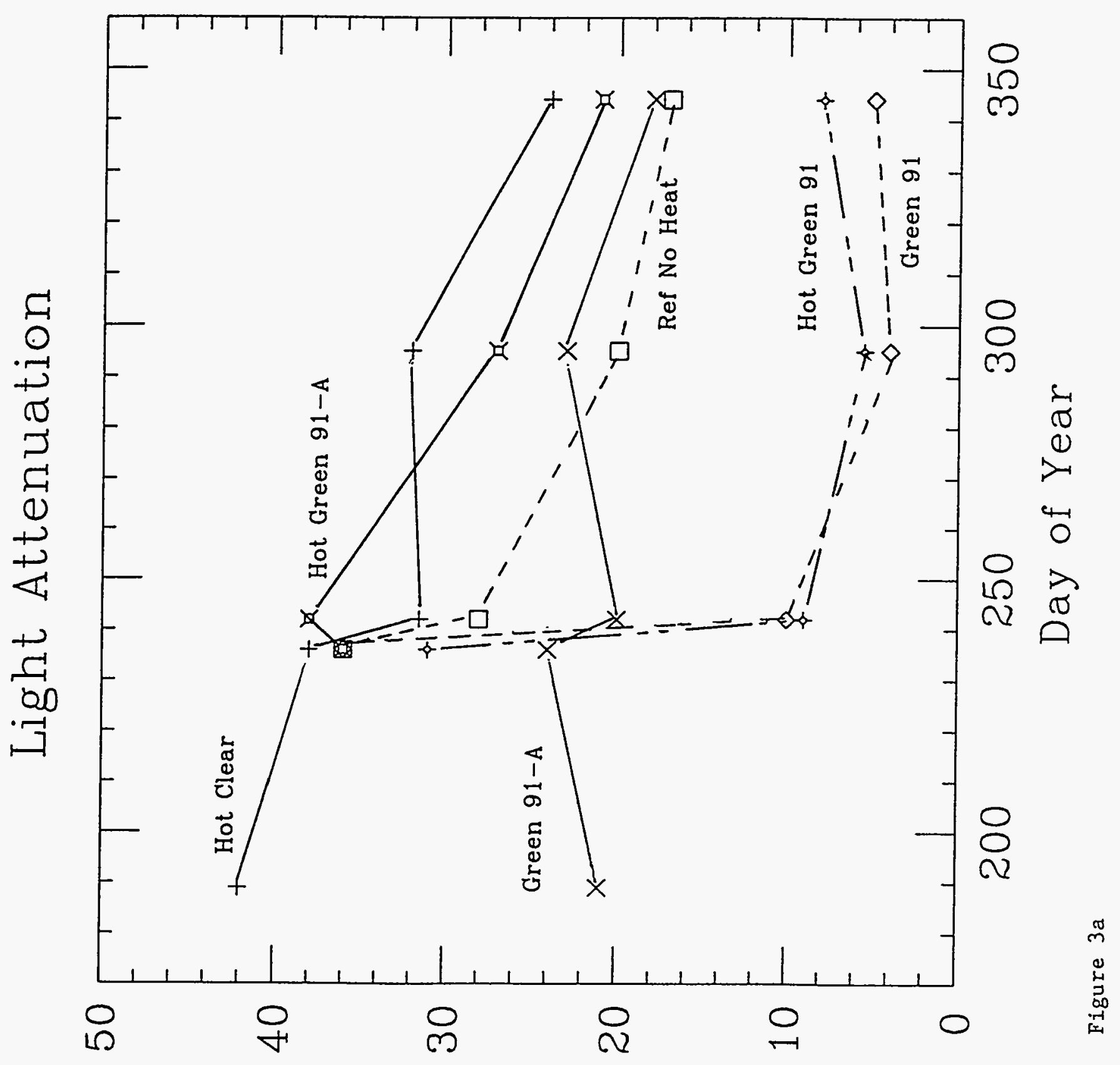

zndzno pəz!̣euton 


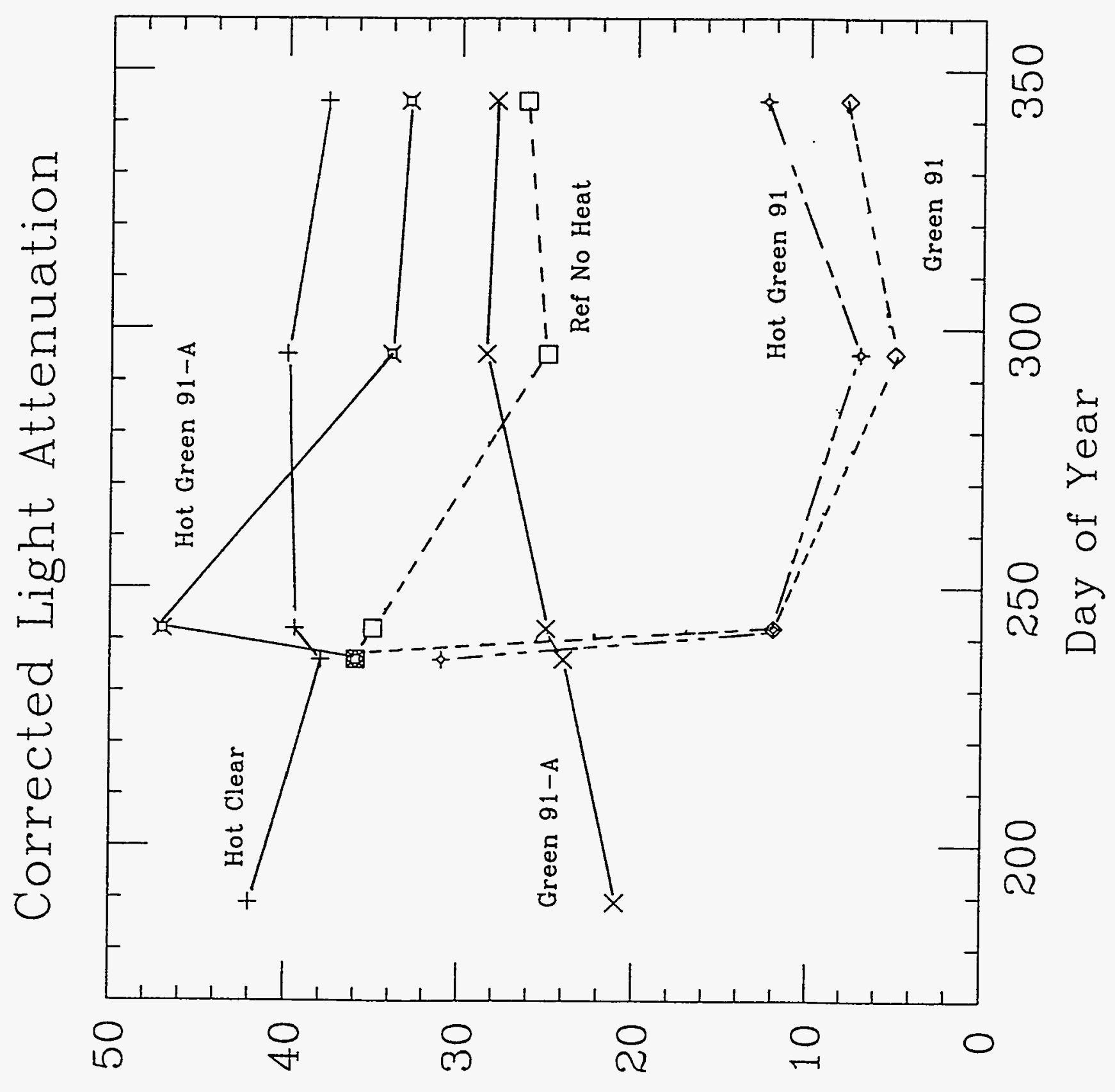

m

zndqno pəz!̣eutoN 


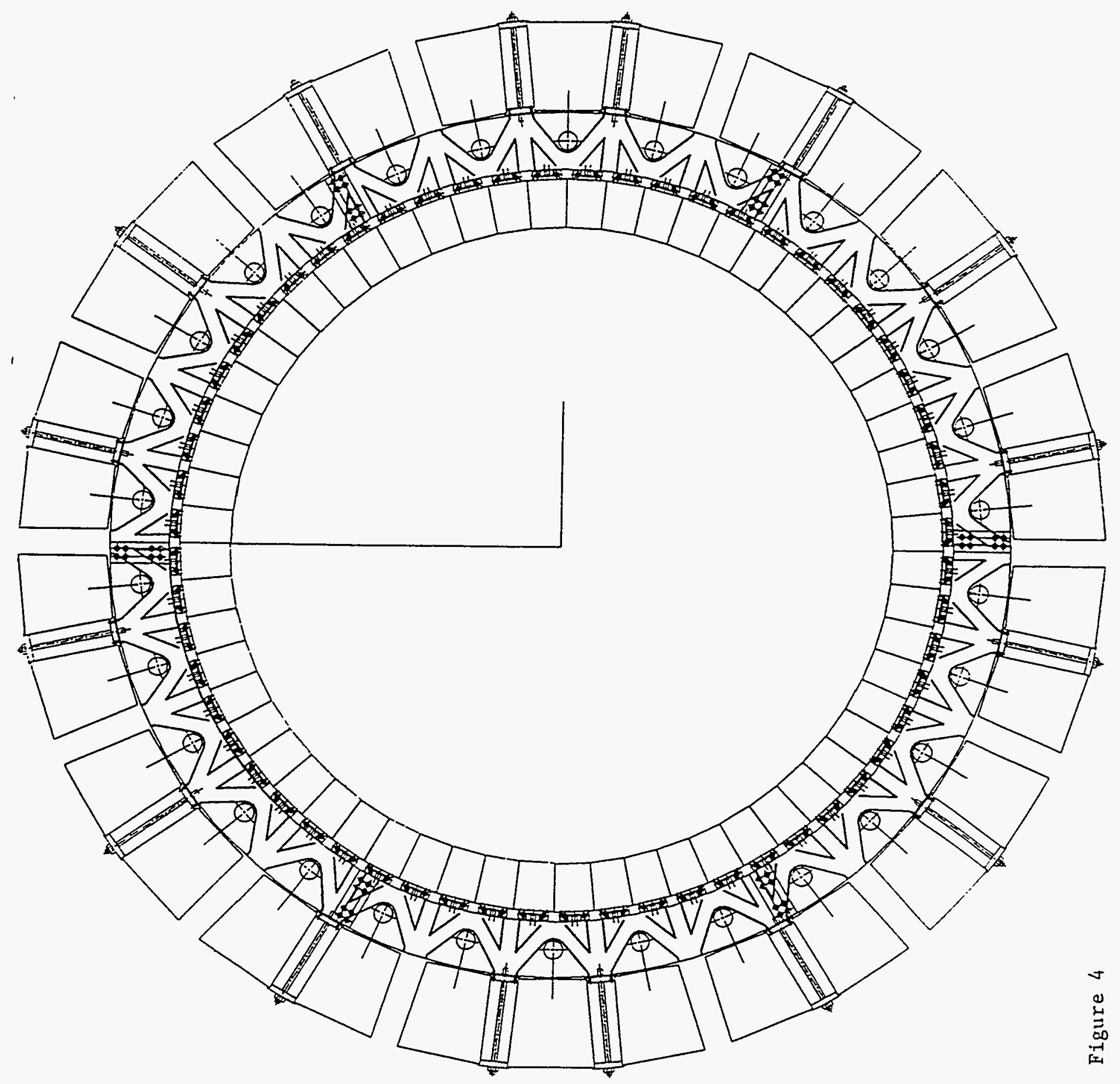




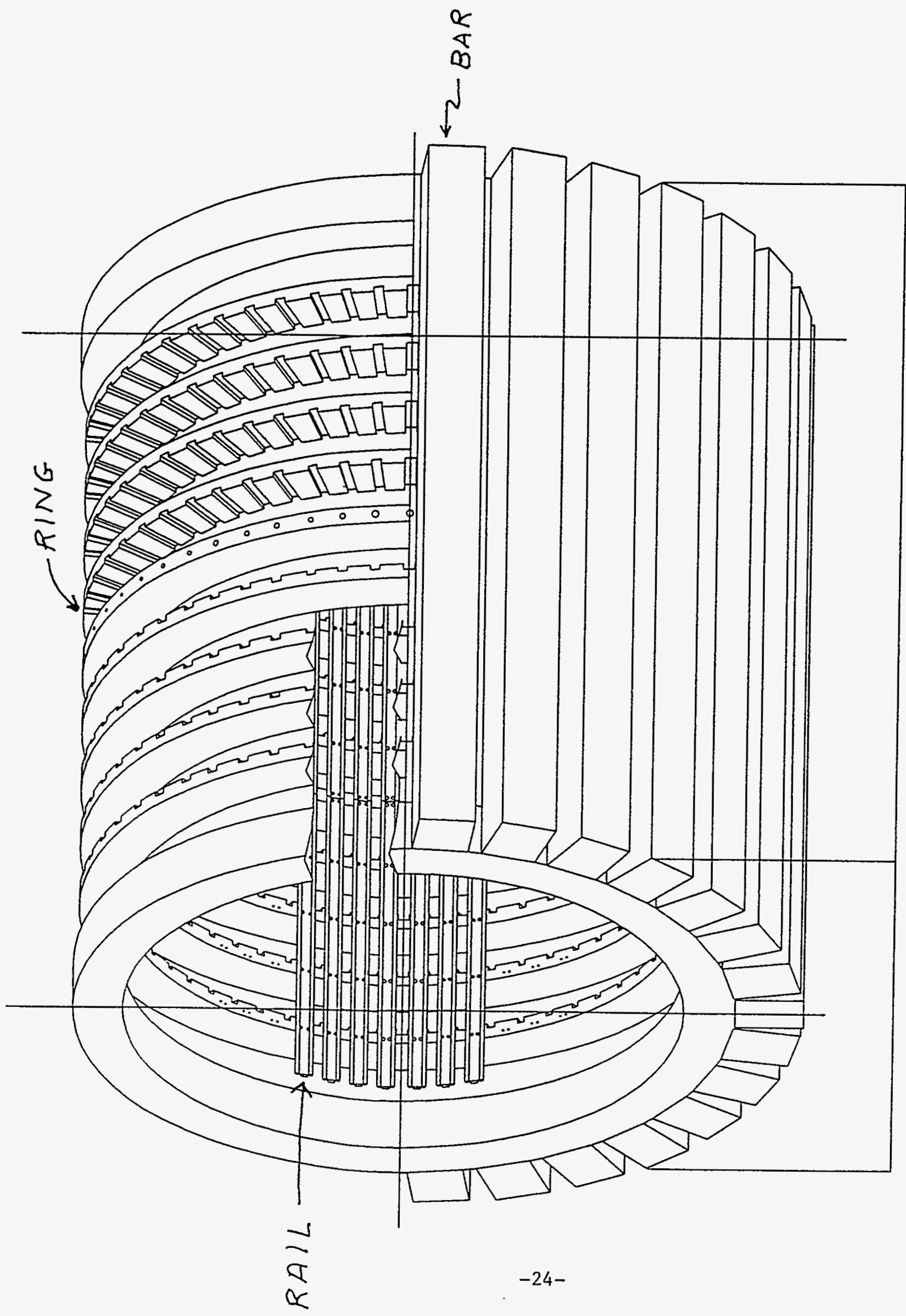

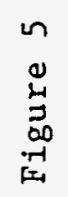




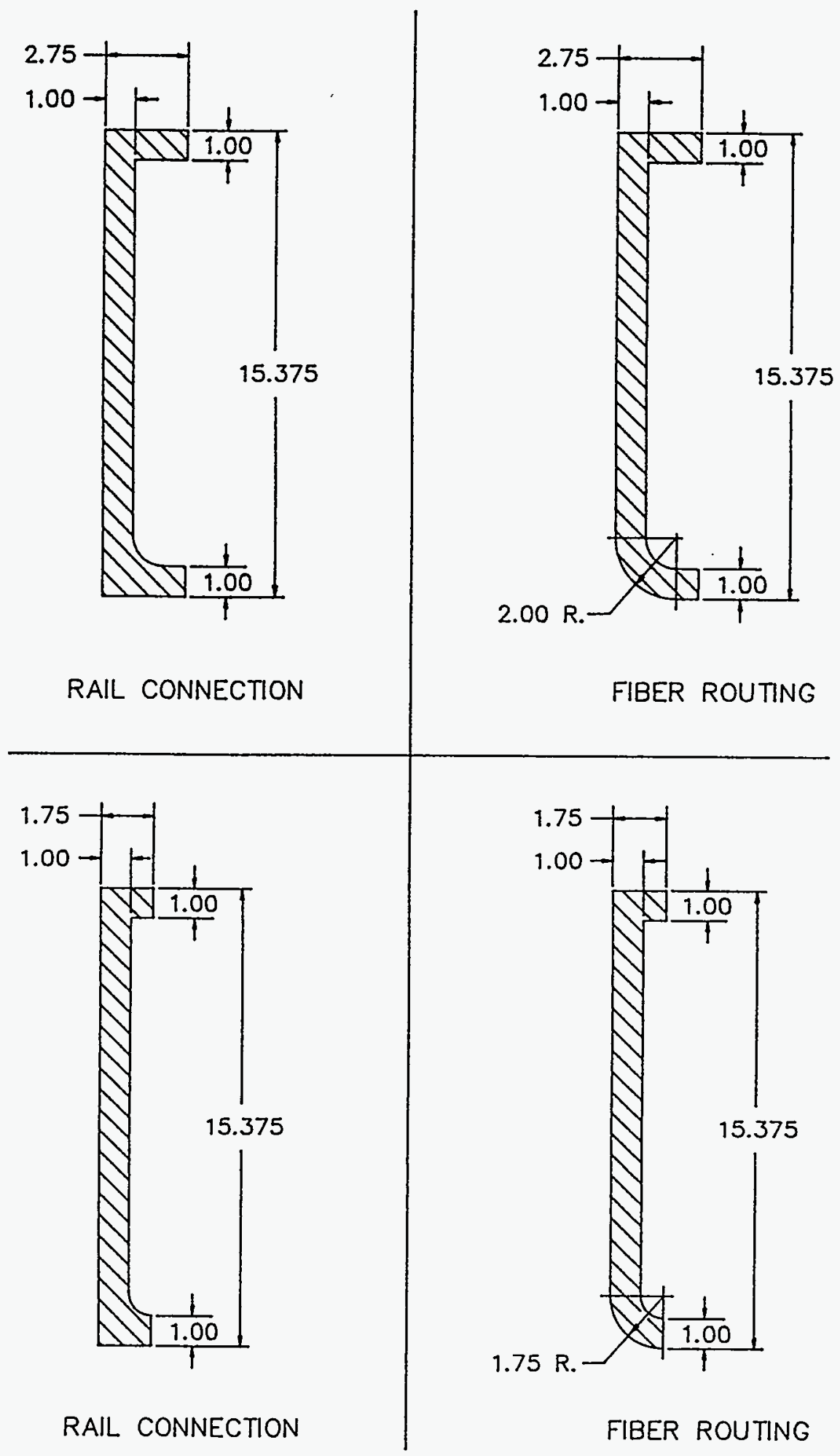

Figure 6 


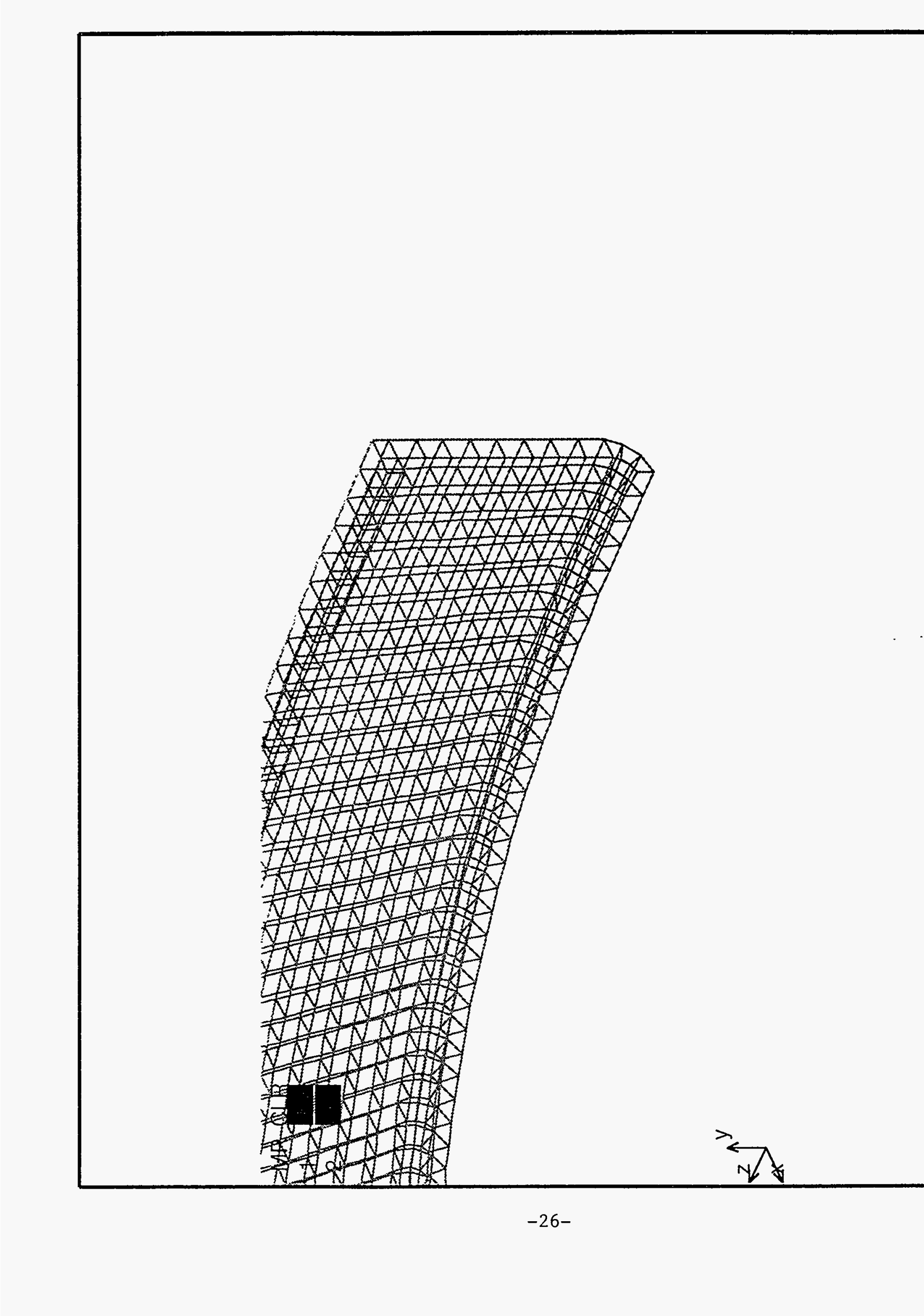




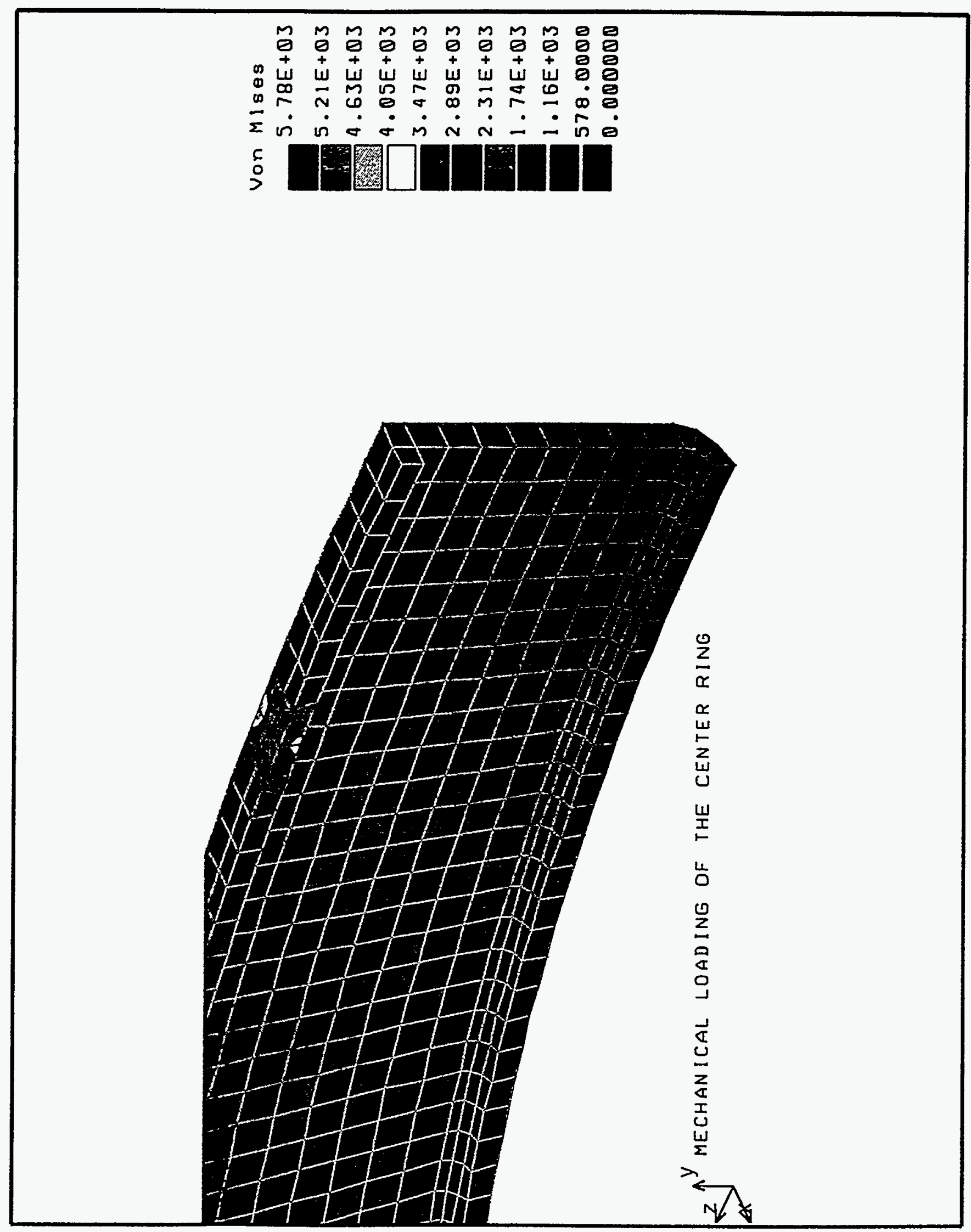

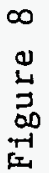




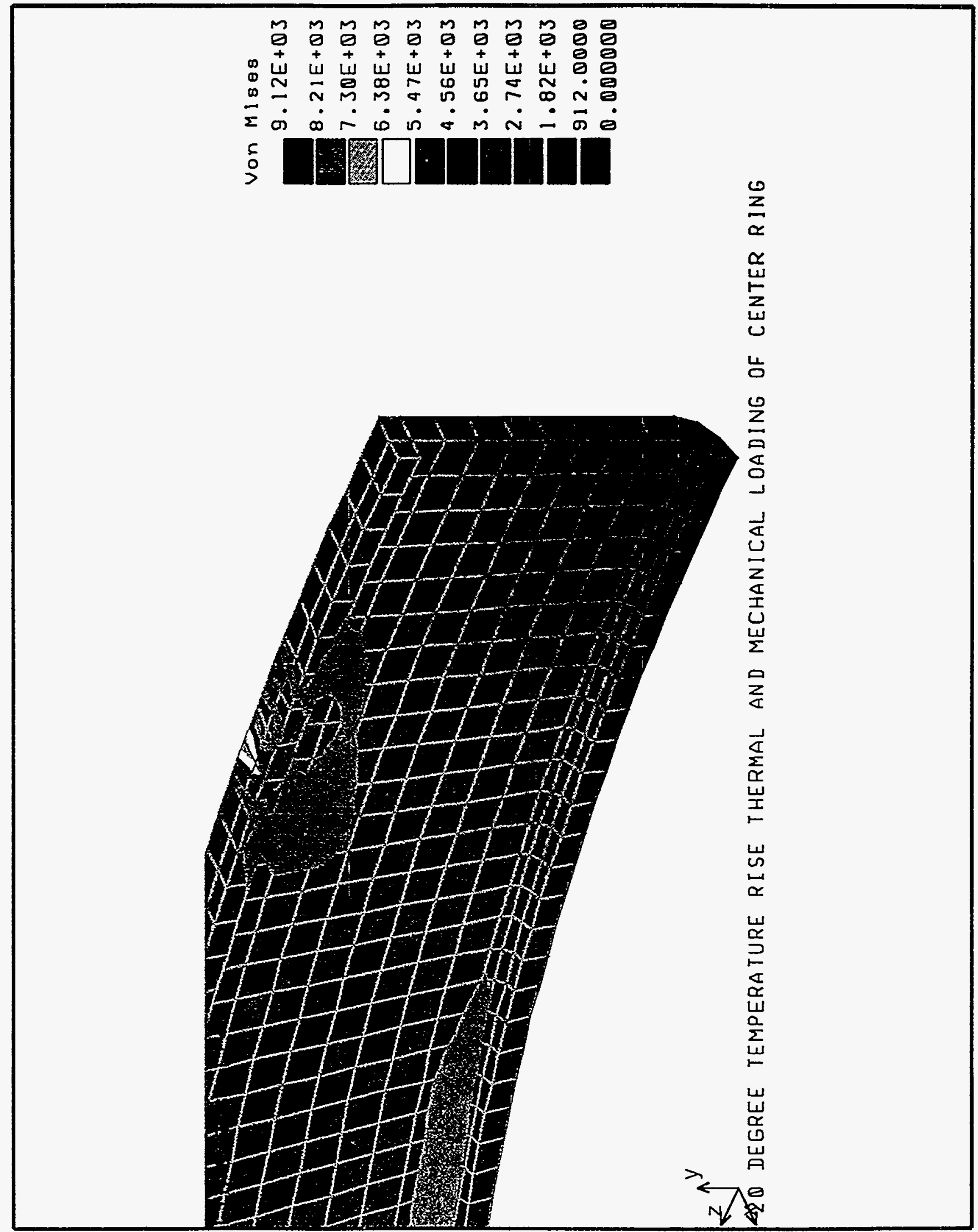

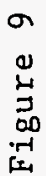




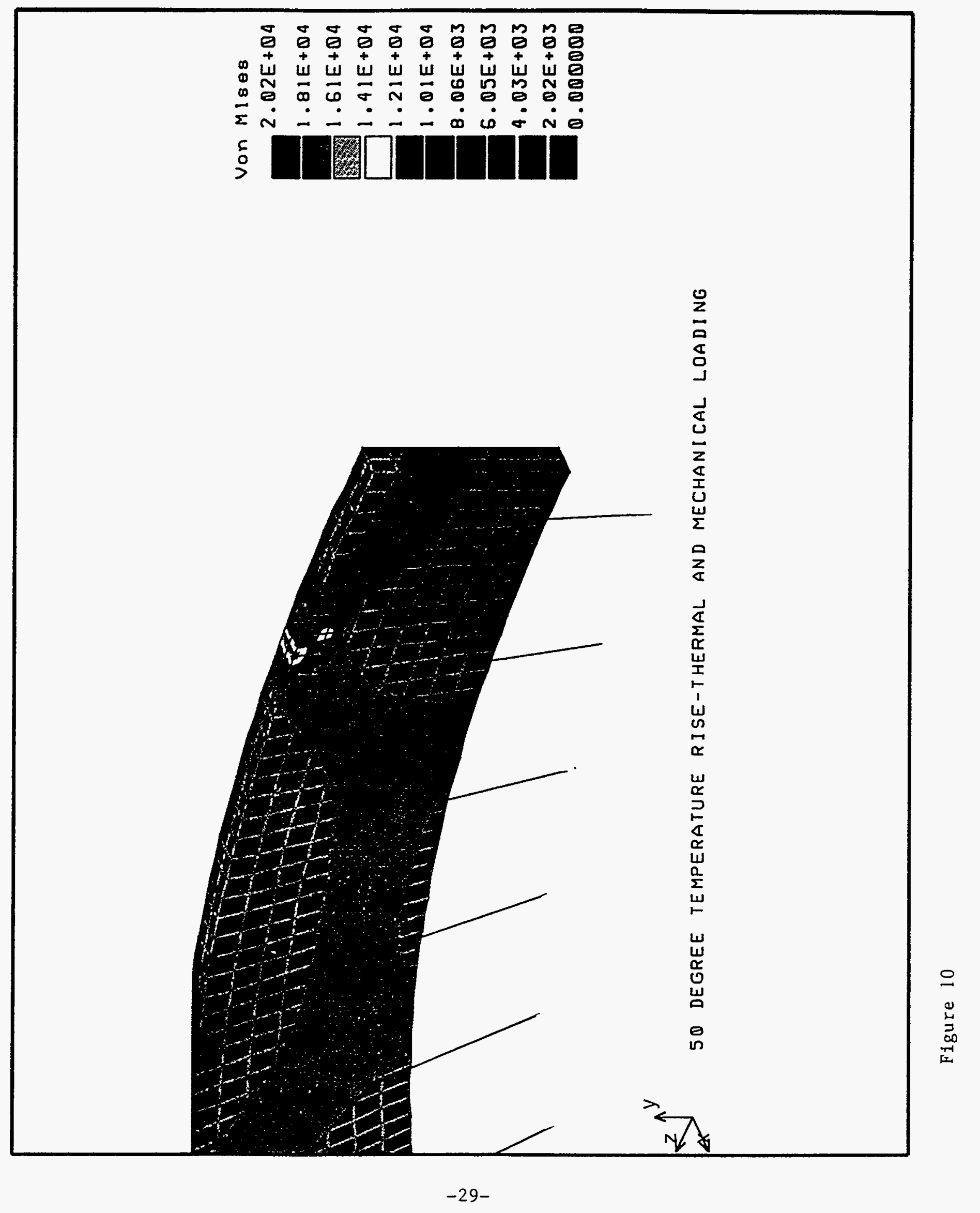




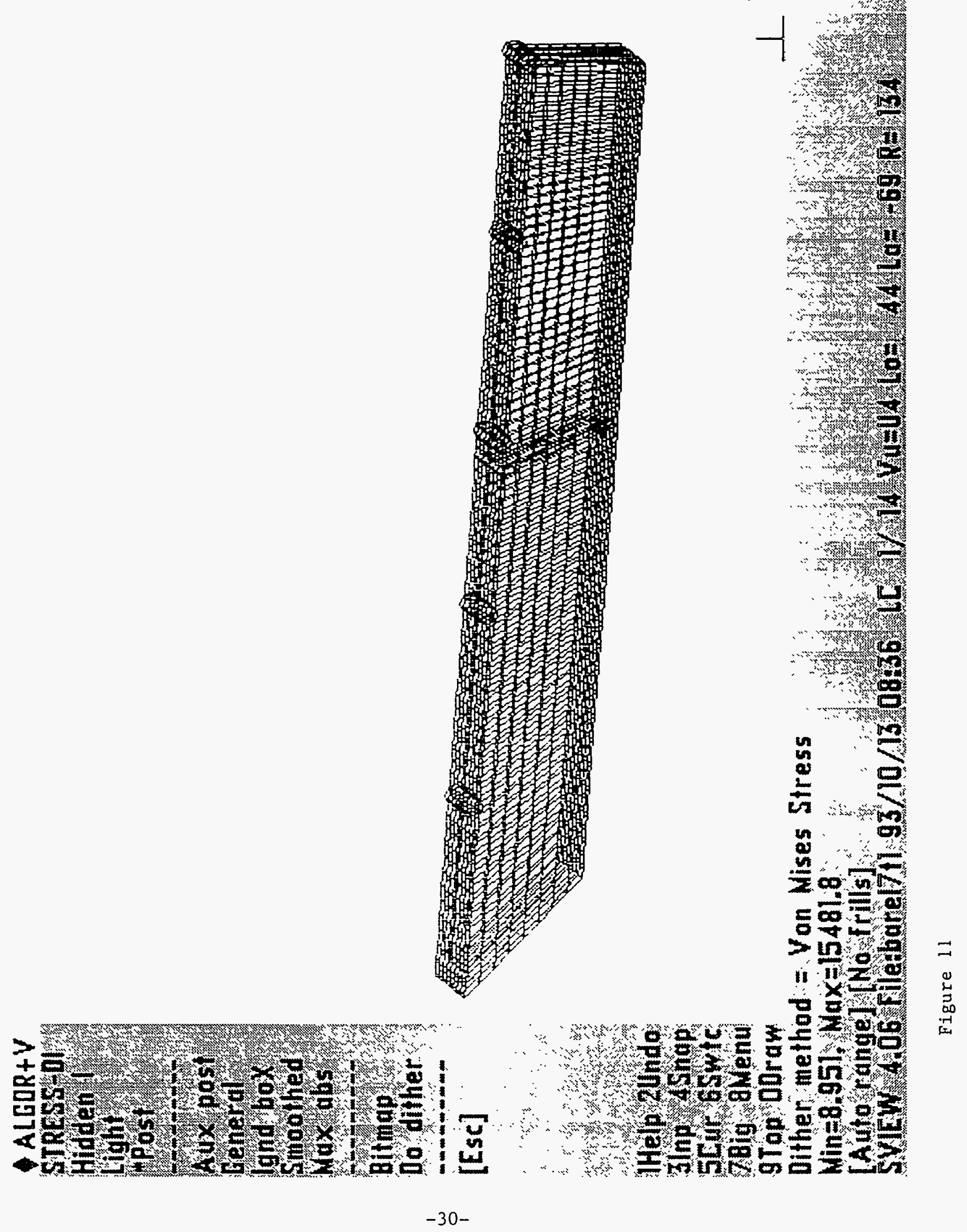



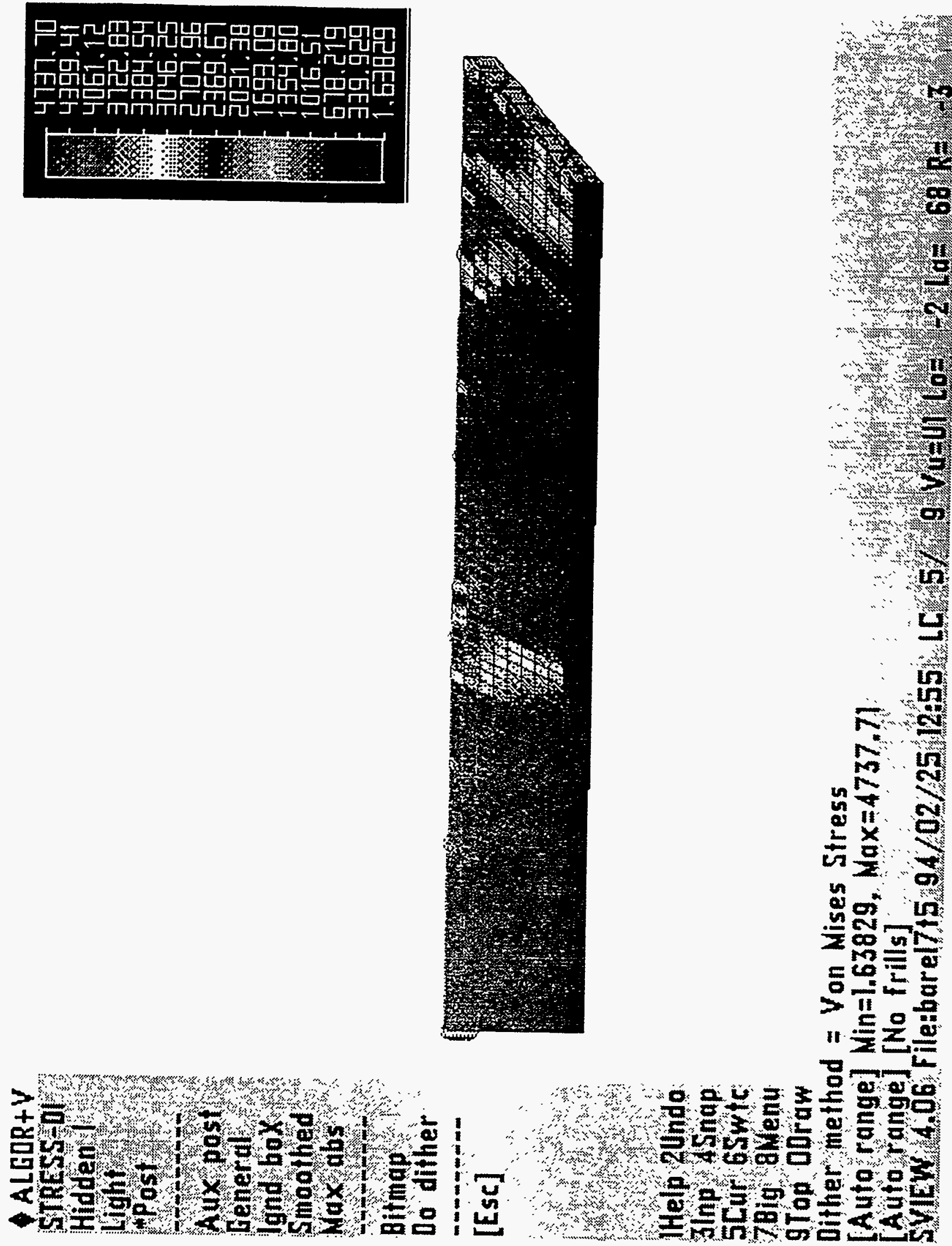

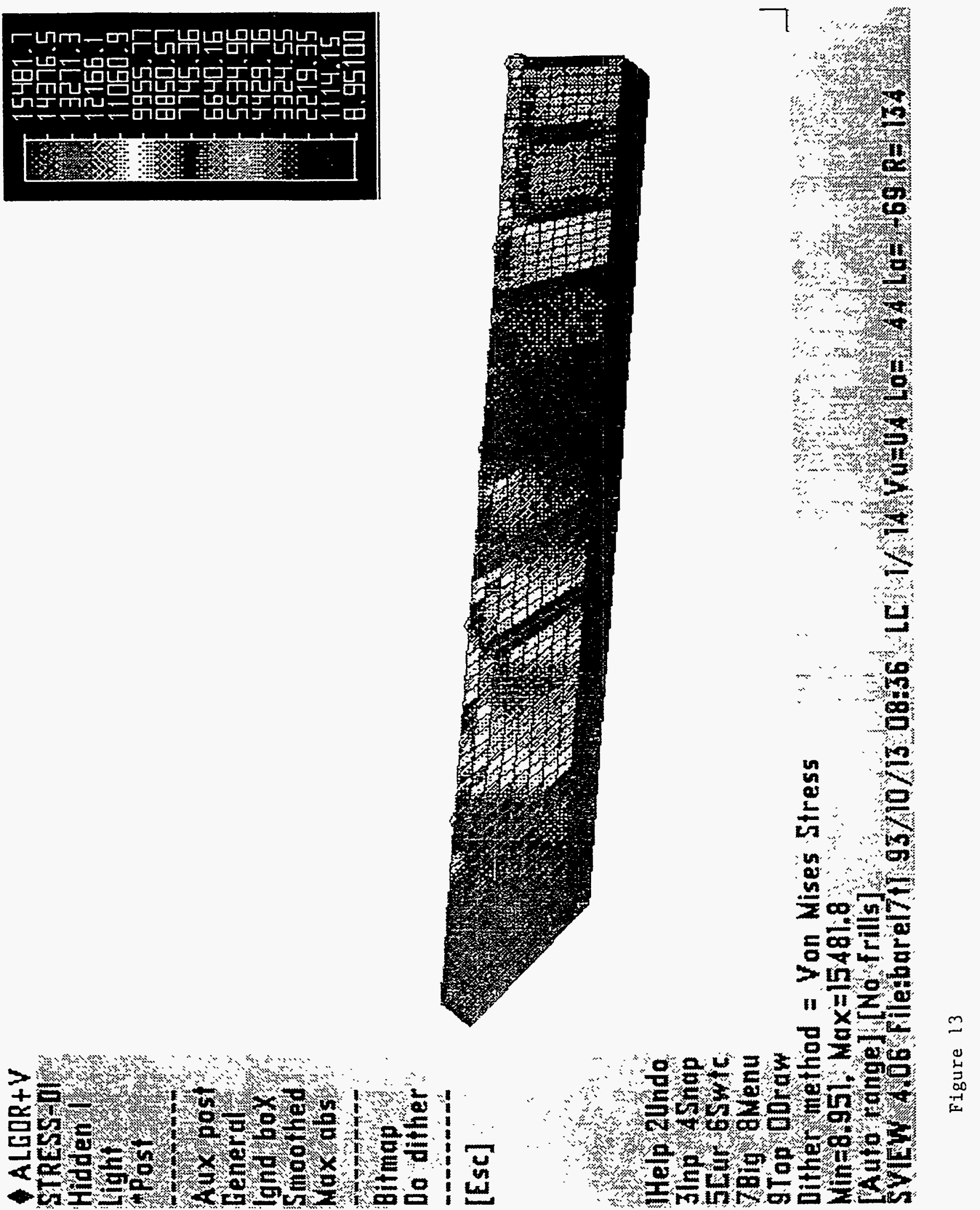

00 in $=5$

$-2=-1$

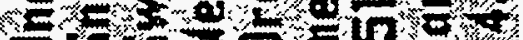

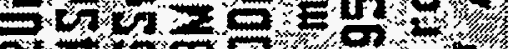



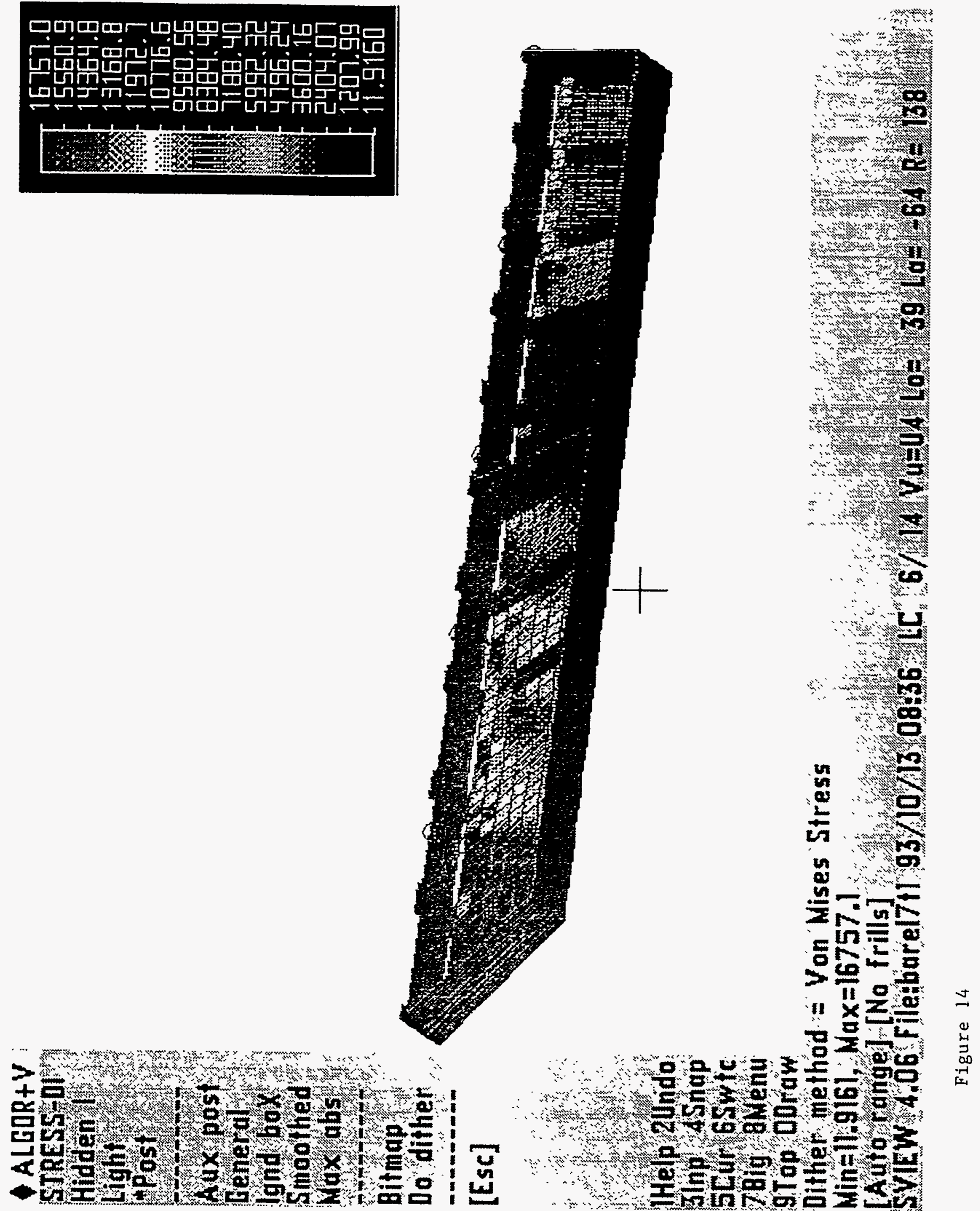


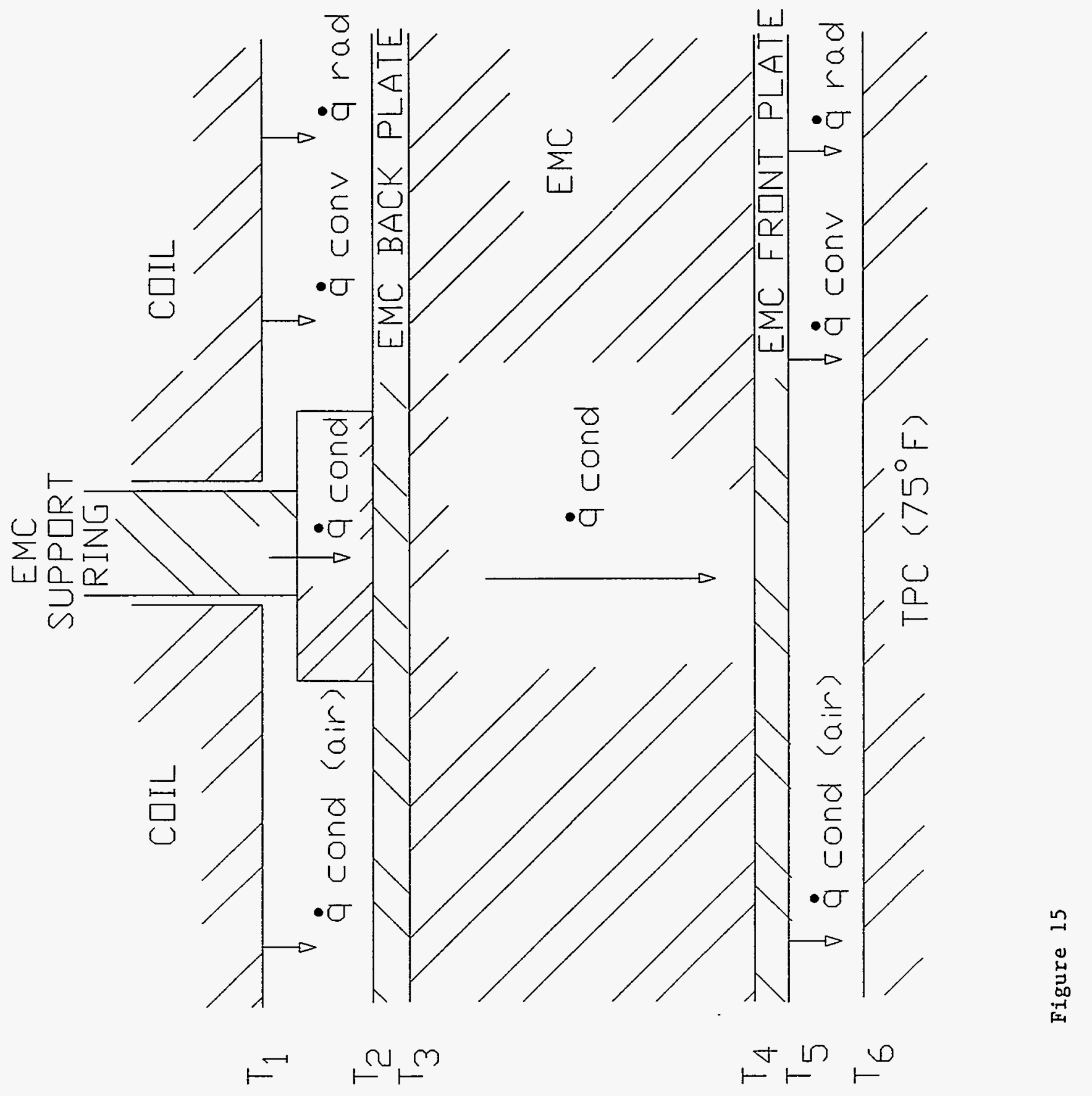


Date: $\quad$ September 1, 1994

To: H. Spinka HEP

From: T. Fornek TD

Subject: Review of the Thermal Calculations Performed on the STAR Barrel Calorimeter Support Structure

References: Thermal Effects on the STAR Electromagnetic Calorimeter, ANL-HEPTR-94-42, Star Note \#177

Per your request for me to review the portions of the subject report based on work performed by Vic Guarino, I have the following comments:

1. The work was performed using the COSMOS Finite Element Computer program. The type of element used in the analysis was an 8- to 20-node isoparametric solid. Vic's initial analysis used the 8-node formulation for the element. The c-shaped cross-section of the support ring was modelled with one element through the thickness. Based on past experience with other finite element programs, I felt that the 8-node element with only one element through the thickness may not be accurate enough. The 20-node element should be better. Vic has run this model with the 20-node element formulation to verify his initial results. Vic found that there was no difference in the results of the analysis using the 20-node element formulation.

2. The loads from the center of gravity of the EMC modules were initially transferred to the solid elements by a single rigid link per support point. This method does not transfer the moments to the element since the solid element only has three defined degrees of freedom per node. Vic reran the model using a tripod rigid link arrangement from the EMC CG to the support ring. This method actually reduced stresses at the support points since the reaction forces at the ring were now distributed between three points. This concern only affects the local stresses at the support points. It is not realistic to expend further resources to expand the model at the support 
locations until more details of the connections are finalized. Future models should take into account the limitations of using rigid links to transfer the EMC loads to the support rings.

Vic ran a simple test case to examine how the rigid link transferred loads to the solid elements. The model consisted of four rectangular solid elements joined in the same plane to form a larger rectangular solid element. The rigid link was connected to a node common to all four elements and extended to a higher elevation than the top of the rectangle. A lateral force was applied to the rigid link. The reactions at the base of the solid elements corresponded to a force applied at the surface of the solid elements and not at the end of the rigid link. This demonstrates that a single rigid link does not transfer moments to the solid elements.

3. One way to confirm the accuracy of the results is to perform an independent analysis of the rings using a different finite analysis program. This is a time-consuming process and may not be possible based on the types of elements and other program-specific concerns. I did run analyses of the rings using the ALGOR finite element program and plate elements. A comparison of average stresses due to deadweight loading from the ALGOR plate results reported in ANL-HEP-TR-94-13 and the COSMOS results reported in ANL-HEP-TR-94-10 show reasonable correspondence for the 2$3 / 4$ " wide $C$-shaped rings supported at sixteen support points per ring. The COSMOS results seem to be lower than the ALGOR Results. One possible explanation for this is that the current ALGOR default plate element formulation seems to produce higher stresses than the previous ALGOR default plate element formulation.

In conclusion, I feel that the work performed sufficiently represents the stress condition in the support rings for preliminary design purposes. More detailed modelling of the support connections may be warranted during later stages of the design.

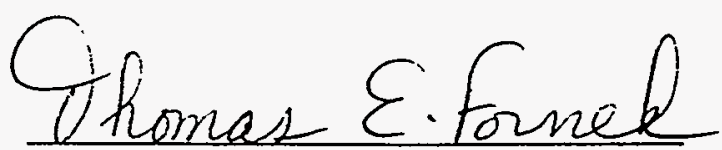

Thomas E. Fornek 


\section{ARGONNE NATIONAL LABORATORY}

9700 South Cass Avenue, Argonne, Illinois 60439

TELEPHONE: 708/252-6277

FACSIMILE: 708/252-5782

BITNET: VJG@ANLHEP

14 October 1994

To: $\quad$ H. Spinka

From:
High Energy Physics Division

High Energy Physics Division

Subject: Check of T, Fornek's Thermal Calculations

I have performed a thermal analysis of the heat transfer between the magnet coils and the CTB with the EMC in place. I assumed that the heat transfer occurred through conduction through the rail supports and through convection. I created an FEA model of the EMC, and imposed the appropriate thermal boundary conditions upon it. I was able to come within $15 \%$ of Tom's calculated heat transmission for temperatures of 115, 105, and 95 degrees Fahrenheit.

VJG/rah 